\title{
Sexual Content in Chinese and British Television Commercials: A Cross-Cultural Comparison
}

\author{
By $\mathrm{Ye} \mathrm{Hao}^{*}$
}

This study compared the use of sexual content in Chinese and British $T V$ commercials. More than 2,400 commercials were collected from two TV channels in Britain and more than 3,000 from three TV channels in China over a two-week sampling period. In this study we measured the prevalence and amount of sexual content in each country's sample commercials, and also made a cross-cultural comparison in terms of the nature of the sexual materials displayed. Results showed that the presence of sex in TV commercials was more prevalent in Britain than in China and that there was a greater quantity of sexual content in British commercials. Few commercials in China and none in China contained nudity, but there was a greater variety of sexual behaviours displayed in British commercials across a wider range of settings and product types. In both countries, there was a greater tendency to display sexual themes in commercials aired late in the evening. Cultural values in each country have resulted in different levels of tolerance for sex in TV commercials.

\section{Introduction}

Sexual themes have been featured as an important aspect of advertising since the earliest days of media advertising in the 19th century (Reichert \& Lambiase, 2014). These themes have continued to be used and their use in advertising has expanded and diversified. Compared to the British regulators (Independent Television Commission, Broadcasting Standards Commission, and the Radio Authority), which carried out a number of studies into the area of sexual content in TV commercials, the study of sex-oriented commercials in China has been rare. This study attempts to fill the existing gap in Chinese research into sex in advertising, and investigate whether the use of sex in advertisements varies across cultures between eastern and western world.

\section{Literature Review}

Sex in Advertising

The earliest research about sex in advertising dates from the 1960s (Sivulka, 2011). At this time, research was focused on whether sexualized

\footnotetext{
*Assistant Professor, Shanghai Jiao Tong University, China.
} 
images of women could enhance brand recall (Alexander \& Judd, 1978; Steadman, 1969). More detailed and systematic attempts to catalogue the prevalence and diverse nature of sexual imagery and themes in advertising emerged in the 1980s. This research examined advertising on television and in print media and coded use of nudity and intimate behaviour in commercial messages. By the late 1990s, evidence emerged that sexual content was displayed in the form of models being in a state of undress or engaged in some form of sexual contacts. Males and females were equally likely to be involved in sexual scenes but females were more often depicted as sex objects (Lin, 1998; Hetsroni, 2012). In addition, there is supportive evidence that sex can sell, especially when it relates to brand recall and creating a positive brand image (Alexander \& Judd, 1978; Severn, Belch \& Belch, 1990, Hardy et al., 2012). Therefore, marketers are using more sex in advertising for a greater range of products. In some markets, the use of sexual imagery is becoming increasingly explicit (Shimp \& Andrews, 2013).

Previous studies of the use of sex in advertising have been characterised by a number of weaknesses. They relied on a very specific definition of sexual content, often restricting the samples to a narrow range of attributes of portrayals, with the level of female nudity being a critical feature (Steadman, 1969; Alexander \& Judd, 1978). It is argued that sexual content can become located by other factors, such as a range of physical and verbal behaviours as well as the physical settings in which actors or models are depicted (see Kunkel, Cope \& Colvin, 1996).

Also, the units of analysis used in earlier content analyses were often limited to the number of sexually-themed advertisements (Soley \& Reid, 1985; Lin, 1998; Reichert, 2003). This unit of analysis is most suitable for examining print advertising, which normally contains imagery of single sexual act or behaviour. However, it is possible for more than one sexual scene or interaction to be contained in a television commercial. So it would be inappropriate to use the number of sexually-themed advertisements to analyse the nature and types of each sexual act featured in TV commercials.

In addition, it should be noted that previous studies tended to use limited samples of television output and did not consider the implications of day-part commercials in relation to the depiction of sex. In some broadcasting jurisdictions, however, there are restrictions placed on the types of content that may be transmitted during specific times of day. In Britain, for example, 9:00 pm represents a critical watershed in this respect (ITC, 1998).

\section{Cross-Cultural Comparisons of Sex in Advertising}

Some researchers started to explore sexuality in advertising across different cultures since the 1990s. For example, Biswas, Olsen and Carlet (1992) conducted a cross-cultural comparison study of print advertisements between the United States and France in terms of emotional appeals, information contents, and uses of humour and sex. Their findings revealed that sexual appeals were depicted in advertisements in both countries, but French advertisements contained more sex appeals than American. However, this 
study lacked a specific definition of sex appeals and systemic coding sheets. All advertisements were coded according to the subjective judgement of the coders. The different cultural background of coders may cause ambiguities.

In 1996, Piron and Young simply compared the level of nudity between German and U.S. women's magazine advertisements in 1986, 1989, and 1992. They noted that, although a shift in the use of showing flesh was observed over time, German advertisements contained less nudity than U.S. advertisements.

In 1997, Cheng compared the gender roles portrayed in Chinese and US television commercials and reported that Chinese women wore less sexually suggestive clothing than their US counterparts. The results suggested that in both countries advertising contained more men in occupational roles and more women in decorative situations. In addition, gender-role portrayals were also found to have much to do with the product categories being advertised (Cheng, 1997).

A recent study of cross-country boundaries research was conducted by Nelson and Paek in 2005. They examined the degrees of sexuality in advertising within Cosmopolitan magazine across seven countries (Brazil, China, France, India, South Korea, Thailand, and the United States). Their findings showed that even within a transnational Western magazine, degrees of sexuality were various. This study was also concerned with the differences which existed in the way that women have been portrayed cross-culturally. It is worth pointing out that Chinese advertisements showed much lower degrees of sexuality than other countries did, and there was a high contrast between domestic and international models in terms of the level of nudity (Nelson \& Paek, 2005). The problem of the study was that it restricted its analysis to the level of sexuality by only examining the level of explicitness. It ignored the nature of sexual behaviour portrayed in advertising which could influence the level of sexuality as much as nudity.

Whilst sexual content in television advertising has been long studied in Britain, there is little research of this kind in China, especially in terms of a cross-cultural comparison. To fill in the gap, this paper intends to compare the use of sexual contents in Chinese and British TV commercials. The research question is as follows:

What are the key differences in the use of sex in TV commercials in

Britain and China?

Specially, we make a cross-cultural comparison in terms of the prevalence, number, length, airtime, product types, visual references, and verbal references in sex-containing commercials on Chinese and British television.

\section{Methodology}

Advertising Samples

The Chinese advertising samples were videotaped from two national (CCTV1 and CCTV2) and one local (Wenzhou TV) TV channel, and the British advertising samples were drawn from two national television networks 
(ITV1 and Channel 4). Regarding the former, recordings were made from CCTV1 between $1^{\text {st }}$ and $14^{\text {th }}$ November 2009, from CCTV2 between $15^{\text {th }}$ and $28^{\text {th }}$ November 2009, and from WTV between $9^{\text {th }}$ and $22^{\text {nd }}$ December 2009. Regarding the latter, recordings were made from Channel 4 between $1^{\text {st }}$ and $14^{\text {th }}$ July 2008 and from ITV1 between $16^{\text {th }}$ and $29^{\text {th }}$ July 2008. All recordings throughout all weeks sampled in both countries were made between $6 \mathrm{pm}$ and $11 \mathrm{pm}$ on seven consecutive days.

A total of 3,086 advertisements were recorded for the Chinese samples (CCTV1 - 1,198; CCTV2 - 1,092; WTV - 796) and 2,405 for the Britain ones (Channel 4- 1,358; ITV1 - 1,047). From these original pools of advertisements, those containing sexual materials were selected for further analysis.

\section{Defining Sexual Content}

Following the works of Kunkel, Cope \& Colvin (1996) and Reichert \& Lambiase (2014) any advertisement that verbally/visually depicted or conveyed a sense of potential of sexual intimacy, interest or motivation was counted in this study.

Specially, sexual content in commercials was coded in four main areas: sexual acts, sexual nudity, gender roles and other variables which make reference to sex. To qualify as a sexual act, a scene must contain at least potential or likely sexual meanings (see Kunkel et al., 1996). For this reason, acts of friendly kissing and touching between friends and relatives were not included. Sexual nudity comprised people revealing their body in adverts in a sexual manner. Voice-overs containing sexual meaning or sex talk in adverts were included. In addition, other allusions and references to objects that had sexual meaning and double entendres were included as sexual content in this study.

\section{Units of Analysis}

This study counted the numbers of commercials that contained sexual materials and then measured 'sexual interactions' within those commercials (see Kunkel, 1996). In this context, an 'interaction' comprised talk or behavioural exchanges involving two or more actors. An interaction was deemed to end when the verbal or overt behavioural exchange between the same characters ceased or the scene terminated or when the nature of the sexual activity changed. Sexual acts (including interactions between two or more actors and actions performed by a single actor) were counted and duration of these acts (in seconds) also measured.

The number of sexual acts depended on the way in which sexual interactions were portrayed in each commercial. For example, kissing and sex talk between characters within the same scene were coded as two sexual acts. Kissing and touching between characters within the same scene were coded as two sexual acts. Several kisses between two characters in same scene were coded as one sexual act, while two kisses in different scenes were coded as two sexual acts. 


\section{Coding Frame}

The coding frame used in this paper comprised of the following elements: codes for general feature of adverts; types of sexual acts; visual references to sex; and verbal references to sex.

\section{General Features}

Five general features were catalogued: (1) the number of commercials; (2) the length of commercials (in seconds); (3) the channel on which the commercials were aired; (4) the transmission time of the commercial (before or after 9pm); and (5) the type of products.

\section{$\underline{\text { Sexual Acts }}$}

Ten sexual act sub-categories, ranging from mild to more graphic sexual activity, were coded: (1) physical flirting; (2) implied sex with products; (3) sexual undressing/bating; (4) kissing on mouth; (5) sexual touching/caressing; (6) sexual intercourse implied; (7) sexual intercourse depicted; (8) sex talk implied; (9) sex talk detailed; (10) others.

\section{Visual References to Sex}

Our coding focused on two categories: nudity and setting. Only nudity that occurred in sexually themed scenes or that conveyed a sexual message was counted. Sub-categories of nudity were guided by audience opinion research conducted in Britain by the ITC (1998): (1) no nudity; (2) partial nudity (wearing underwear); (3) partial nudity (topless-front); (4) nude (behind/side); and (5) nude (frontal).

Setting was classified in the following terms: (1) bedroom; (2) bathroom; (3) living room; (4) occupational setting; (5) leisure (including bar, restaurant);

(6) fantasy; (7) others (including outdoor) and (8) undetermined.

\section{Verbal References to Sex}

Verbal references referred to any voice-overs in commercials that contained sexual meanings. The sub-categories were: (1) mention the word 'sex'/comment about sex directly; (2) allude to sex by means of double entendre; (3) others; and (4) did not convey sexual meanings.

\section{Coding Reliability}

Coding reliability was assessed independently for the British and Chinese commercial samples. An initial reliability sub-sample of 100 commercials was selected for each country. These were each separately coded by two coders using the same codebook.

Reliability was assessed at two distinct levels: agreement on identifying sex-containing adverts and agreement on the codes used to describe the sexual content identified. At level one, inter-coder agreements reached 98\% (the Chinese sample) and 97\% (the British sample). At level two, inter-coder agreement levels of $95 \%$ and $93 \%$ were obtained. 
Vol. 1, No. 2 Hao: Sexual Content in Chinese and British Television Commercials...

\section{Results}

Prevalence of Sex-Containing Advertisements

This study coded a total of 376 advertisements containing sexual content across the Chinese and British networks; 93 from the three Chinese TV channels and 283 from the two British TV Channels. The proportion of sex advertisements in all recorded adverts was around 3\% in Chinese sample and $11.8 \%$ in the British sample. It is clear that British networks contained a significantly higher proportion of sex-containing advertisements compared to the Chinese networks ( $\mathrm{X} 2=162.37 \mathrm{df}=1 \mathrm{p}<0.000)$ [Exact].

Number of Sexual Acts

A total of 105 sexual acts appeared in Chinese advertisements, with CCTV1 showing half $(50 \%)$ of these acts, with the remainder distributed fairly evenly between CCTV2 (23\%) and WTV (28\%). In the British sample, there were 313 sexual acts in advertisements, with 183 (59\%) on Channel 4 and 130 (42\%) ITV1.

\section{Airtime Occupied by Sexual Content in Advertisements}

In total, there were 5,268 seconds (around one and a half hours) of advertisements coded as sex-containing advertisements in this study from the Chinese sample, and 2,839 seconds (more than 47 minutes) of the scenes in those sex-containing advertisements were coded as containing sexual content. Thus, sexual content occupied 44 percent of the total duration of sexcontaining advertisements. WTV contributed most to advertising-based sex on TV in the Chinese sample (85\% of total), with CCTV1 (10\%) and CCTV2 $(5 \%)$ contributing much less (see Table 1 ).

In the British sample, there were a total of 6,012 seconds (around one hour 40 minutes) of sex-containing advertising. The duration of sexual content within these advertisements (2,655 seconds or more than 44 minutes) amounted to $39 \%$ of their duration. Nearly three-quarters of this sexual content (74\%) occurred in advertisements on Channel 4 (see Table 1.)

Table 1.Duration (seconds) of Sex-containing Commercials \& Sexual Content

\begin{tabular}{|l|l|l|l|l|l|l|l|}
\hline & \multicolumn{4}{|l|}{ Chinese Commercials } & \multicolumn{3}{l|}{ British Commercials } \\
\hline & CCTV1 & CCTV2 & WTV & Total & Channel4 & ITV1 & Total \\
\hline $\begin{array}{l}\text { Sex-Containing } \\
\text { Commercials }\end{array}$ & 1275 & 414 & 3579 & 5268 & 4027 & 1985 & 6012 \\
\hline Sexual Content & 229 & 109 & 1981 & 2319 & 1969 & 686 & 2655 \\
\hline
\end{tabular}

Sex and Product Type

About three out of four (74\%) of the sex-containing advertisements appearing on Chinese television networks were coded under four product categories 'beauty and personal care products', 'domestic', 'bedding' and 'underwear'. There were no 'motoring', 'service' ,'travel', 'movies' or 
'electronic' commercials using sexual appeals to promote products in the Chinese sample.

'Beauty and personal care' products were again the dominant product category containing sexual content in advertisements from British television (39\% of total). The second most popular products using sex content in British television were 'food and beverages' $(16 \%)$. There were no advertisements coded under the 'underwear', 'bedding' or 'sex disease and treatment' categories in the British sample (see Table 2).

Comparisons between countries revealed significantly greater use of sexual content in advertisements in China for underwear and bedding products and sex disease services and greater use sex in Britain in advertisements for different $\mathrm{CD} /$ music, domestic items, food and beverage, motoring, movies and electronic goods (see Table 2).

Table 2. Product Types Related to the Use of Sexual Themes in Advertisements

\begin{tabular}{|c|c|c|c|c|c|c|c|c|}
\hline & \multicolumn{4}{|c|}{ Chinese Commercials } & \multicolumn{4}{|c|}{ British Commercials } \\
\hline Product Types & CCTV1 & CCTV2 & WTV & Total & Channel4 & ITV1 & Total & \\
\hline \begin{tabular}{|ll} 
Beauty and \\
Personal \\
Care Product
\end{tabular} & 19 & 6 & 2 & 27 & 58 & 51 & 109 & n.s \\
\hline Fashion & 0 & 6 & 0 & 6 & 0 & 7 & 7 & n.s \\
\hline Underwear & 0 & 0 & 14 & 14 & 0 & 0 & 0 & 14.67 \\
\hline Bedding & 8 & 2 & 1 & 11 & 0 & 0 & 0 & 30.44 \\
\hline CD/Music & 0 & 0 & 0 & 0 & 21 & 5 & 26 & 9.18 \\
\hline Domestic & 19 & 0 & 0 & 19 & 14 & 5 & 19 & 14.50 \\
\hline $\begin{array}{l}\text { Food } \\
\text { Beverage }\end{array}$ & 0 & 4 & 5 & 9 & 36 & 8 & 44 & n.s \\
\hline Motoring & 0 & 0 & 0 & 0 & 10 & 11 & 21 & 7.31 \\
\hline Service & 0 & 0 & 0 & 0 & 0 & 4 & 4 & n.s \\
\hline Travel & 0 & 0 & 0 & 0 & 0 & 6 & 6 & n.s \\
\hline $\begin{array}{l}\text { Sex Disease and } \\
\text { Treatment }\end{array}$ & 0 & 0 & 5 & 5 & 0 & 0 & 0 & 11.59 \\
\hline Movies & 0 & 0 & 0 & 0 & 22 & 3 & 25 & 8.80 \\
\hline electronic & 0 & 0 & 0 & 0 & 22 & 0 & 22 & 7.68 \\
\hline Other & 0 & 2 & 0 & 2 & 0 & 0 & 0 & n.s \\
\hline Total & 46 & 20 & 27 & 93 & 175 & 108 & 283 & \\
\hline
\end{tabular}

\section{Types of Sexual Content in Commercials}

An overwhelming majority of sexual actions in Chinese sample comprised fairly mild flirting behaviour (84\%). Small numbers of recorded acts comprised bathing or undressing (9\%), talk about sexual themes $(5 \%)$ and suggestive sexual behaviour with the product (3\%). In the British advertisements, again a clear majority of sexual acts involved flirting behaviour (70\%), followed by kissing on the mouth (10\%), sexual talk (8\%), sexual touching $(6 \%)$ and undressing $(3 \%)$. Hence there was more variance in sexual content in British advertisements than I Chinese advertisements. 
Further statistical tests revealed that a number of sex-related actions that were significantly more prevalent in British advertisements than in Chinese advertisements: flirting (X2 $=8.04, \mathrm{df}-1, \mathrm{p}<0.01)$; kissing on the mouth $(\mathrm{X} 2$ $=11.62, \mathrm{df}=1, \mathrm{p}<0.01)$; sexual touching $(\mathrm{X} 2=4.99, \mathrm{df}=1, \mathrm{p}<0.05)$.

\section{Visual References to Sex}

Nudity in Commercials

More Chinese $(80 \%)$ than British (59\%) advertisements contained no nudity $(\mathrm{X} 2=12.86$, df $=1 ; \mathrm{p}<0.01)$. In the Chinese advertisements, only partial nudity (actors in underwear) was ever shown (20\% of sex-containing advertisements) whereas in British advertisements a substantial minority depicted partial nudity (40\%), a small number (four advertisements or $2 \%$ of the total) depicted nudity (shown from behind).

\section{Physical Setting of Sexual Acts}

In Chinese sample sexual content was depicted primarily in the bedroom $(46 \%)$ and the bathroom (17\%). Other settings that featured in this context were outdoor $(3 \%)$ and leisure settings $(12 \%)$, with a small number $(7 \%)$ in settings that could not be clearly determined. In British television advertisements, sexual content was distributed across a wider range of settings: bedroom (30\%), outdoor (27\%), bathroom (14\%), occupational setting (9\%), leisure setting $(8 \%)$, living room $(6 \%)$ and fantasy $(3 \%)$ or undetermined settings $(3 \%)$. There were statistically significant differences between British and Chinese advertisements in the extent to which sexual content occurred in the bedroom $(\mathrm{X} 2=9.01$, df $=1, \mathrm{p}<0.01$; more so in China), occupational setting $(\mathrm{X} 2=9.68, \mathrm{df}=1, \mathrm{p}<0.01$; more so in Britain) and outdoor setting ( $\mathrm{X} 2$ $=8.31, \mathrm{df}=1, \mathrm{p}<0.01$; more so in Britain).

\section{Verbal References to Sex}

The findings indicated that 70 percent sexual acts in Chinese sample contained voice-overs, with female voice-overs $(\mathrm{n}=59 ; 80 \%)$ significantly outnumbering males $(\mathrm{n}=14 ; 19 \%)(\mathrm{X} 2=55.48 \mathrm{df}=1 \mathrm{p}<0.000)$ [Exact].

Turning to the British sample, there were about 43 percent sexual acts contained voice-overs. 28 percent of them were by males and the other were by females. Hence once again, female voice-overs significantly outnumbered males $(\mathrm{X} 2=48.13 \mathrm{df}=1 \mathrm{p}<0.000)$ [Exact].

Of the 73 voice-overs in sex-containing television adverts in the Chinese sample, most $(n=68 ; 93 \%)$ did not contain any sexual meanings. But it is worth to point out that five voice-overs in advertisements on WTV mentioned the word 'sex'. These all came from sexual disease treatment commercials appearing on this channel during the sampling period.

Turning to the British sample, of the 135 voice-overs in sex-containing advertising, again most $(\mathrm{n}=112 ; 83 \%)$ voice-overs did not contain any sexual meanings. There were 21 voice-overs (16\%) alluding to sex in British advertisement sample which used words such as 'seduce' and 'attractive' to try to arouse people's sexual association. 


\section{Discussion}

British television advertisements contained far more sexually-themed material than did Chinese television advertisements. Not only were there fewer advertisements on the Chinese television channels that contained any sexual content than was true of those appearing on the sampled British television channels, but there was also significantly less sexual content on average within those advertisements that contained any sex at all in British than in Chinese televised advertisements.

It may reflect important differences in the traditional cultural values British and Chinese societies. There is in turn stricter censorship of advertisements in China than in Britain. The Chinese state religion, Confucianism, holds conservative attitudes towards sex-related issues. These traditional values have shaped Chinese society for thousands years. In particular, under the control of the New Confucianist ideology, sex was a taboo subject in the late imperial period in China (960-1911 C.E.).

After the P.R. China was established, traditional sexual morals were reasserted; discourse on sex was not forbidden but was restrained in limited areas. However, in 1966 and 1967 when the Cultural Revolution swept the whole of Chinese society, discourse on sex was strictly banned in Chinese society again and the slightest suggestion of sexual interest was considered ideologically unsound. After the restrictions of the Cultural Revolution, sexual attitudes and behaviour changed in China, but Confucianism still impacts Chinese society in every aspect (Ruan, 1991). The Chinese censorship authority, SARFT, holds a stricter attitude with regard to issues related to sexual material in the media compared to the British censorship authority (SARFT, 2010).

Despite the lower overall amount of sex in advertising on television in China, one of the three Chinese television channels - WTV had longer sexcontaining advertisements than one of the two British television channels ITV1. It might be due to the Chinese regularity authorities fail to exert the same control over services based further away from Beijing. Another explanation is that WTV carries a lot of programme-length commercials which increased the average length of its advertisements.

In both Britain and China, beauty and personal care products and domestic products were most frequently associated with the use of sexual themes. Apart from these findings, however, sexual themes were often linked to different product ranges in televised advertising in each country. The association of sexual themes with beauty and personal care products confirms earlier findings (Gunter; 2002; Cheng, 2002).

In China, sexual themes were quite often also associated with underwear and bedding products, but did not feature in relation to these ranges in Britain. Sexual themes in Britain were often featured in televised advertisements for food and beverage products, motoring products, movies and electronic items, but rarely featured in these areas in China. These findings once again revealed 
a more liberal attitude towards the use of sexual themes as a marketing device in western advertising than in eastern advertising.

It is also worth pointing out that the underwear advertisements broadcast on WTV breached the Chinese advertising codes for promoting female products of this kind and, according to audience research conducted in China these advertisements presented a risk of offending Chinese audiences (Cheng, 2002).

Public opinion research conducted in Britain and the United States has previously been found to accept the use of sexual themes in advertisements for beauty products and underwear, but was progressively less accepting of its use for other product categories (Gunter \& Wober, 1990; Reichert, 2003). In general, audience research has indicated that viewers are more likely to accept sexual themes and nudity in advertisements if they are relevant to the product being promoted (Gunter, 2002). In contrast, research in China has revealed that viewers are much less tolerant of the use of sex and nudity even in beauty and underwear products where they may appear in the west to be more relevant (Fam \& Waller, 2003).

In both countries, there was a stronger tendency to broadcast advertisements with sexual themes after 9pm. In Britain, this represents a critical watershed after which restrictions of broadcast content are gradually relaxed as it is presumed that the children's audiences will rapidly decline after this hour. For Britain, this finding indicates that advertisers and broadcasters have adopted practices that would receive the support of viewers who have been found to support restrictions on the use of sexually-themed promotions, particularly if they contain nudity, to post-9pm (ITC, 1998).

In general, the sexual content in television advertisements in both countries was mild in nature. There was more likely to be sexual content featuring nudity and some degree of intimate touching in British television advertisements than in Chinese television advertisements. There was some evidence of explicit talk about sex and a number of these incidents (five in all) occurred in advertisements shown on WTV. According to previous audience research (Cheng, 2002) and the advertising codes authorized by SARFT in China, these advertisements ran a risk of causing public offence and may have breached advertising codes.

The level of intimate sexual content found in British television advertisements in this analysis was similar to that found in an earlier study of advertisements on US network television by Lin (1998). Throughout all this research, however, sexual content was more usually implied than explicitly portrayed. In addition, there were few verbal references to sex in voice-overs in either country.

More explicit depictions of sexual themes tend to be manifest in terms of nudity. This was rare in British television advertisements and completely absent in the Chinese sample. From a total of 3,086 Chinese television advertisement analysed in this study, only $19(0.006 \%)$ contained any nudity. The absence of complete nudity even in the apparently more liberal television 
advertising environment in Britain, confirms to public opinion preferences in respect of the use of such content (Beetles \& Harris, 2004).

In terms of settings for sex, advertisements on Chinese television contained more sexually-themed activity in bedroom settings than did the British sample. Even so, the bedroom was the most popular setting for sex in advertising in both countries. In contrast, the British sample contained much more sexually-themed activity in occupational settings and outdoor settings than the Chinese sample. In general, the distribution of settings in British sexcontaining advertisements showed a wider range than Chinese sex-containing advertisements. These results are consistent in many ways with research about sex on television programmes conducted in the United States, which found that the bedroom and work settings were the most popular locations for sexual activity to take place (Greenberg et al., 1986).

Sex was found to occur more often in televised advertisements in Britain than in China. 'Sex in British advertisements occurred in association with a wider array of products and in a more diverse array of settings than was the case for the Chinese sample. In general, the use of sex in television advertising was reserved in nature, but was somewhat more explicit in British advertisements. The findings provide evidence that the use of sex appears to be more selective advertising in China than in Britain. While it is used as a sales technique in both markets, there may be greater sensitivity in China to cultural values-related tolerances for use of sexual themes in advertising.

\section{Reference}

Alexander, W. M., and Judd, B. Jr. 1978. Do nudes in ads enhance brand recall? . Journal of Advertising Research. 18(1), 47-51.

Beetles, A. C. and Harris, L.C. 2004. Female nudity in advertising: an exploratory study. Gender and Consumer Behaviour. 7, 45-51.

Biswas, A., Olsen, J., and Carlet, V. 1992. A comparison of print advertisements from the United States and France. Journal of Advertising. 21(4), 73-81.

Cheng, H. 1997. Holding up half of the sky? a socio-cultural comparison of genderrole portrayals in Chinese and U.S. advertising. International Journal of Advertising, 16, 259-319.

Cheng, H. 2002. A Hong Kong view of offensive advertising. Journal of Marketing Communication. 8(2), 234-256.

Fam, K. S., and Waller, D.S. 2003. Advertising controversial products in the Asia pacific: what makes them offensive? Journal of Business Ethics. 48, 237-250.

Greenberg, B. S., Stantley, C., Siemick, M., Heeter, C., Soderman, A., and Linsangen, R. 1986. Sex content on soaps and primetime television series most viewed by adolescents (Project Cast Report No.2). East Lansing: Michigan State University, Department of Telecommunication.

Gunter, B. 2002. Media Sex: What is the issues? London: Lawrence Erlbaum Associates.

Gunter, B., and Wober, M, .1990. Television and advertising: the public's view. London: Independent Broadcasting Authority.

Hardy,K., Kingston,S. Sanders,T. 2012. New Sociologies of Sex Work. 
Ashgate Publishing, Ltd.

Hetsroni, A. 2012. Advertising and Reality: A Global Study of Representation and Content. Bloomsbury Publishing.

ITC (Independent Television Commission, 1998). Television: The public's view --. 1997. London, UK: Author.

Kunkel, D., Cope, K. M., and Colvin, C. 1996. Sexual messages on family hour television: Content and Context. Menlo Park CA: Kaiser Family Foundation.

Lin, C. A. 1998. Uses of sex appeals in prime-time television commercials. Sex Roles. 38(5/6), 461-475.

Nelson, M. R. and Paek, Hye- Jin 2005. Cross-Cultural Differences in Sexual Advertising Content in a Transnational Women'. Sex Roles.53(5/6), 371-383.

Piron, F., and Young, M. 1996. Consumer advertising in Germany and the United States: a study of sexual explicitness and cross-gender contact. In L. A. Manrai, and Manrai, A. K.(eds.), Global perspectives in cross-cultural and cross-national consumer research. New York: International Business, 9-22.

Reichert, T. 2003. The prevalence of sexual imagery in ads targeted to young adults. Journal of Consumer Affairs. 37, 403-412.

Ruan, F. F. 1991. Sex in China: Studies in Sexology in Chinese Culture. Plenum Press.

SARFT 2010. Report on development of China's radio film and television 2010. Xinhua Press.

Severn, J., Belch, G. E., and Belch, M. A. 1990. The effects of sexual and non-sexual advertising appeals and information level on cognitive processing and communication effectiveness. Journal of Advertising. 19(1),14-22.

Shimp, T. \& Andrews, J. C. 2013. Advertising Promotion and Other Aspects of Integrated Marketing Communications. South-Western: Cengage Learning.

Sivulka, J. 2011. Soap, Sex, and Cigarettes: A Cultural History of American Advertising. Wadsworth: Cengage Learning.

Soley, L., and Reid, L. 1985. Baiting viewers: Violence and sex in television program advertisements. Journalism Quarterly. 62(1),105-110,131.

Steadman, M. 1969. How sexy illustrations affect brand recall. Journal of Advertising. 9(1), 343-353.

Reichert, T. \& Lambiase, J. 2014. Sex in Advertising: Perspectives on the Erotic Appeal. Routledge. 